\title{
Cyan $\mathrm{Ni}_{1-\mathrm{x}} \mathrm{Al}_{2+2 \mathrm{x} / 3} \square_{\mathrm{x} / 3} \mathrm{O}_{4}$ single phase pigments synthesis and modification for electrophoretic inks formulation.
}

Béatrice Serment‡, Manuel Gaudon, ${ }^{+*}$, Alain Demourgues', Amélie Noë^, Guillaume

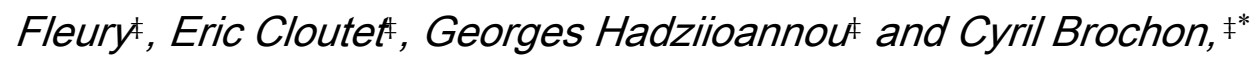

+ CNRS, Univ. Bordeaux, Bordeaux INP, ICMCB, UMR 5026, F-33600 Pessac, France

‡Univ. Bordeaux, CNRS, Bordeaux INP, LCPO, UMR 5629, F-33615, Pessac, France

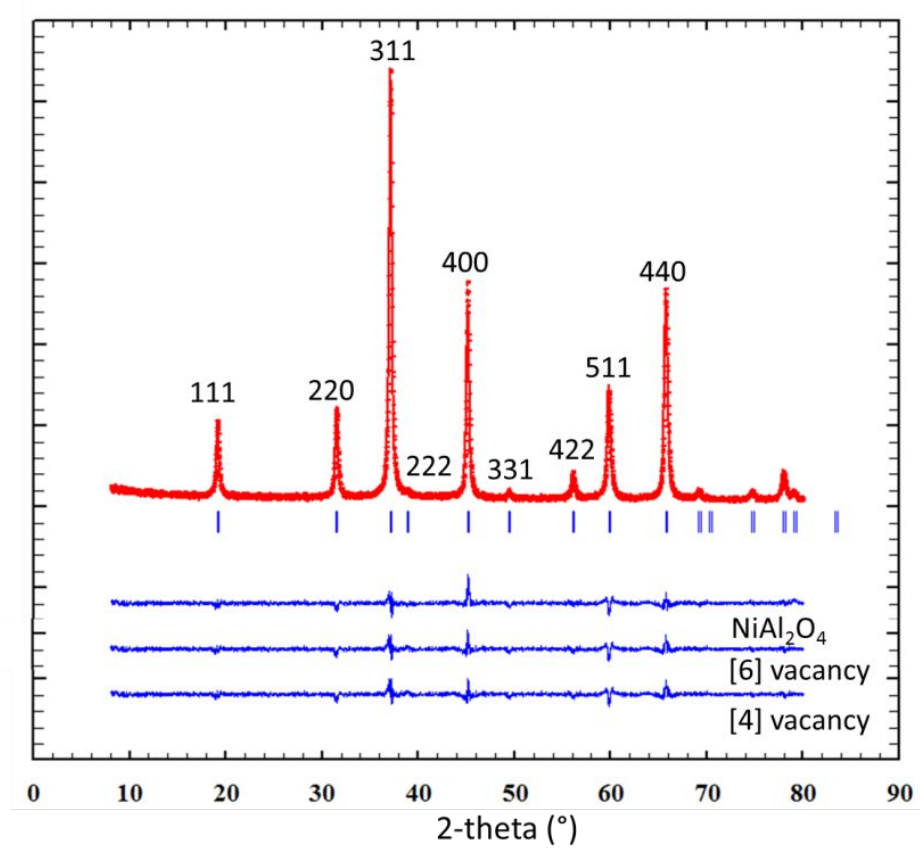

Figure SI-1. Rietveld refinement plot on the $\mathrm{Ni} / \mathrm{Al}=0.4$ pure spinel compound (experimental signal and signal differences between experimental and calculated diffractograms) considering the three refinement procedures: (i) $\mathrm{NiAl}_{2} \mathrm{O}_{4}$ stoichiometric composition, (ii) cationic vacancies located in octahedral sites and, (iii) cationic vacancies located in tetrahedral sites. 


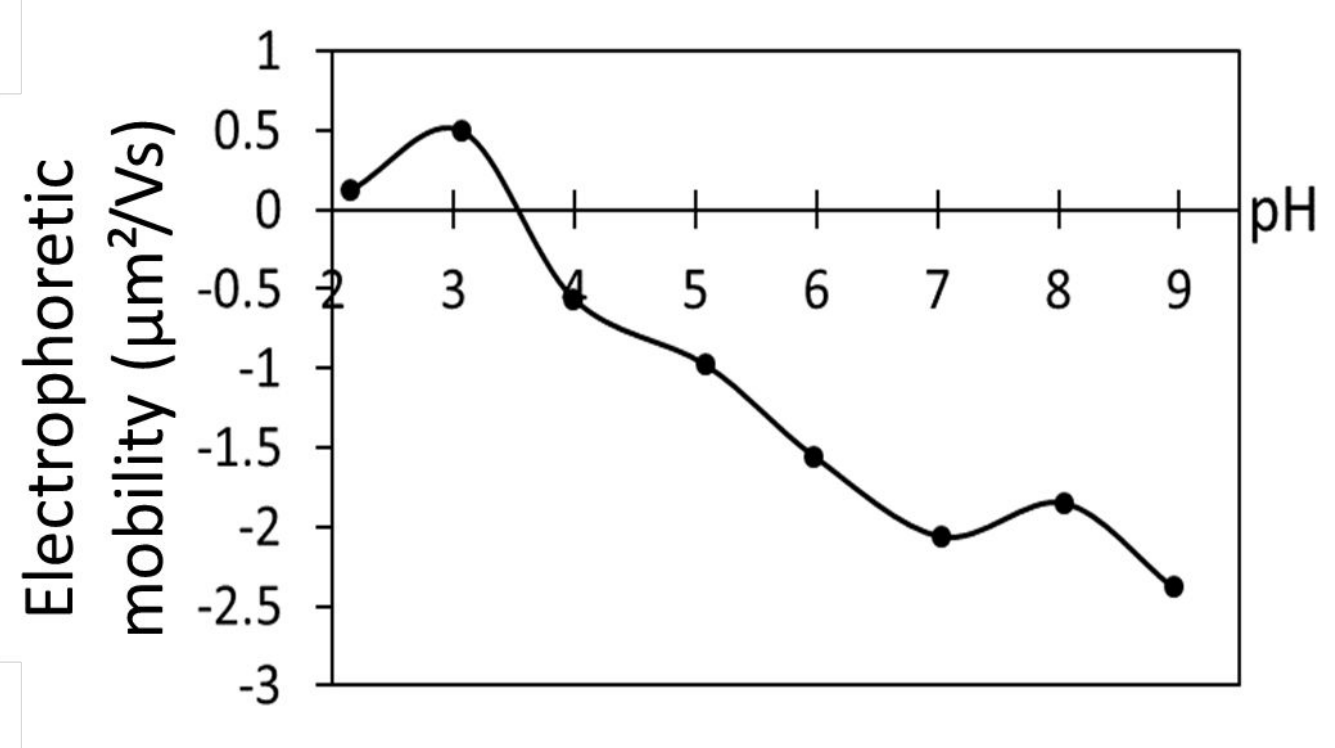

Figure SI-2. Evolution of the electrophoretic mobility versus the $\mathrm{pH}$, on $\mathrm{Ni}_{1-\mathrm{x}} \mathrm{Al}_{2+2 \mathrm{x} / 3} \mathrm{O}_{4}$ compound (with $\mathrm{Ni} / \mathrm{Al}$ ratio $=0.40$ ), dispersed in water to obtain the isoelectric point of the pigment.

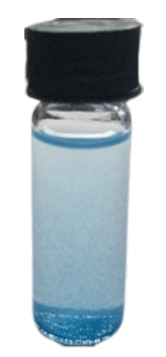

Before silanization

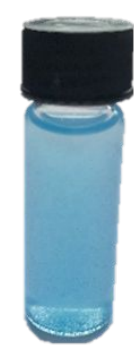

After silanization

Figure SI-3. Pigments dispersed in Isopar G before and after silanization.
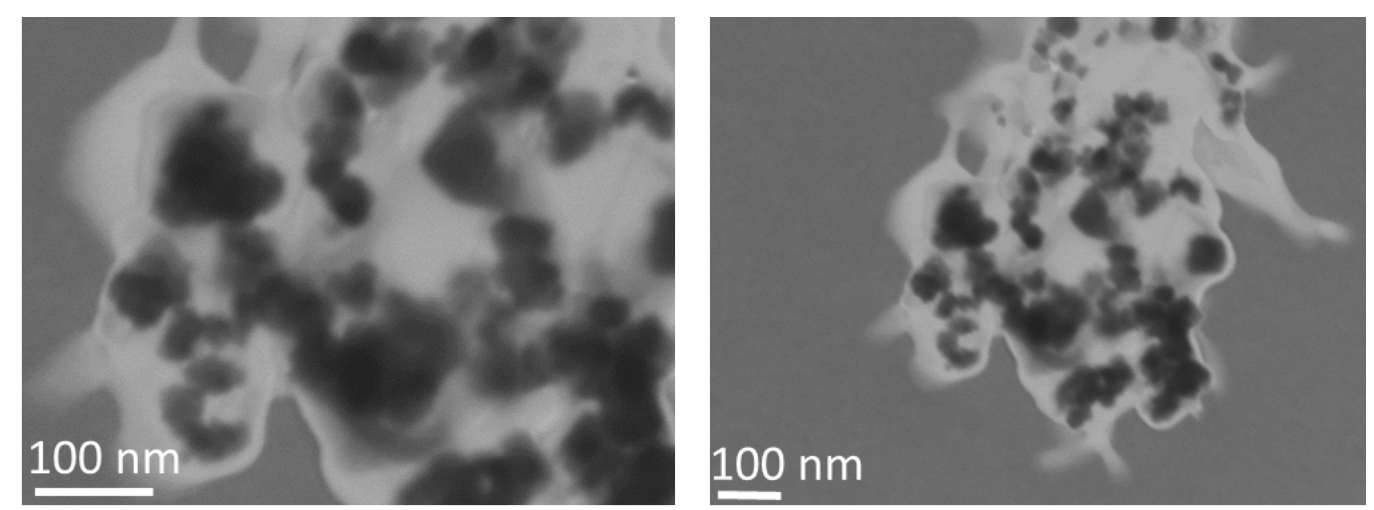

Figure SI-4. STEM image of $\mathrm{Ni}_{0.84} \mathrm{Al}_{2.11} \square_{0.05} \mathrm{O}_{4}$ hybrid modified with $5 \mathrm{v} / \mathrm{v} \%$ of OTS and polymerised with $10 \mathrm{v} / \mathrm{v} \%$ of MMA. 


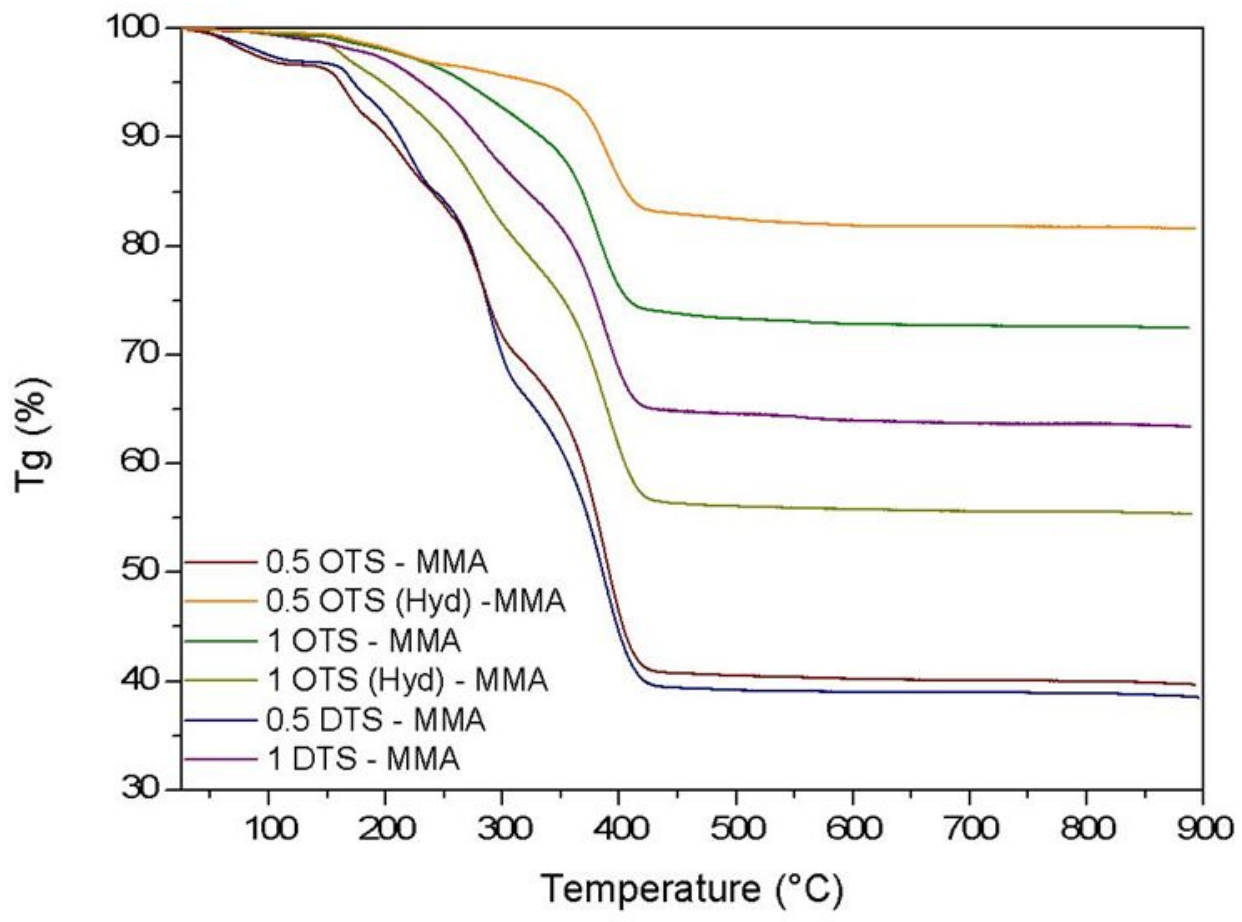

Figure SI-5. TGA curves of as prepared hybrids core-shell particles.

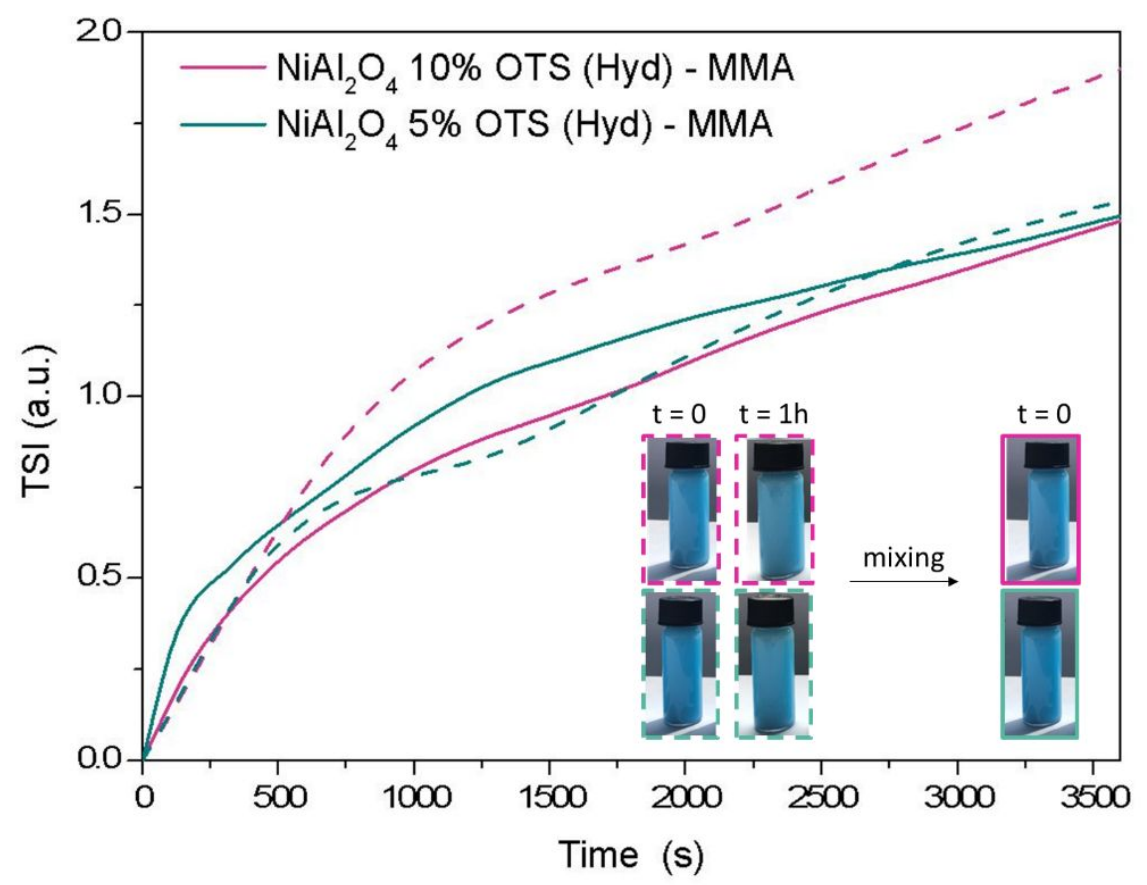

Figure SI-6. Evolution of the Time Sedimentation Index (TSI) with the time for hybrid particles after synthesis and mixed after 2 months. Insert, photographies of dispersions before measure, after $1 \mathrm{~h}$ without the mixture and after 2 months. Solid lines represent inks mixing after 2 months and dotted lines inks after polymerisation. 